\title{
Advances in Ceramic Matrix Composite Blade Damping Characteristics for Aerospace Turbomachinery Applications
}

\author{
J. B. $\operatorname{Min}^{1}$ \\ NASA-Glenn Research Center, Cleveland, Ohio, 44135 \\ D. L. Harris ${ }^{2}$ \\ NASA-Marshall Space Flight Center, Huntsville, Alabama, 35812 \\ and \\ J. M. Ting ${ }^{3}$ \\ Foster-Miller, Inc., Waltham, Massachusetts, 02452
}

\begin{abstract}
For advanced aerospace propulsion systems, development of ceramic matrix composite integrally-bladed turbine disk technology is attractive for a number of reasons. The high strength-to-weight ratio of ceramic composites helps to reduce engine weight and the onepiece construction of a blisk will result in fewer parts count, which should translate into reduced operational costs. One shortcoming with blisk construction, however, is that blisks may be prone to high cycle fatigue due to their structural response to high vibration environments. Use of ceramic composites is expected to provide some internal damping to reduce the vibratory stresses encountered due to unsteady flow loads through the bladed turbine regions. A goal of our research was to characterize the vibration viscous damping behavior of $\mathrm{C} / \mathrm{SiC}$ composites. The vibration damping properties were measured and calculated. Damping appeared to decrease with an increase in the natural frequency. While the critical damping amount of approximately $2 \%$ is required for typical aerospace turbomachinery engines, the $\mathrm{C} / \mathrm{SiC}$ damping at high frequencies was less than $0.2 \%$ from our study. The advanced high-performance aerospace propulsion systems almost certainly will require even more damping than what current vehicles require. A purpose of this paper is to review some work on $\mathrm{C} / \mathrm{SiC}$ vibration damping by the authors for the NASA CMC turbine blisk development program and address an importance of the further investigation of the blade vibration damping characteristics on candidate CMC materials for the NASA's advanced aerospace turbomachinery engine systems.
\end{abstract}

\section{Introduction}

$I^{\top}$ Thas been a widely held assumption that fiber-reinforced composite materials possess more inherent material damping than metals or monolithic composites [1-2]. Ceramic matrix composites (CMC) possess high-strength, low-weight, and high-temperature capability. These are desirable attributes for turbopump turbine-end component materials [3]. Although the use of ceramic matrix composites promises many advantages in aerospace turbomachinery engine development, the most beneficial aspect of CMCs may be the material's capability that may allow new designs to operate to over $2400^{\circ} \mathrm{F}$. Increased temperature capability can also operate more efficiently by providing additional benefit in payload capacity due to the decreased weight with more capable materials.

A typical inserted blade configuration uses some combination of devices to deal with severe dynamic stresses due to random vibration induced in the blade area. These devices which provide some form of vibration damping include shrouds and dampers in the gap of the blade root between blade and disk. Generally a metallic integrallybladed turbine disk (blisk) provides little or no damping. Without damping there is degradation in blisk life typically

\footnotetext{
${ }^{1}$ Structures and Dynamics Branch, Research \& Technology Directorate, MS 49-8, AIAA Associate Fellow.

${ }^{2}$ Structural Dynamics, Propulsion Systems Department, MC ER41.

${ }^{3}$ Materials Engineering, Formerly Foster-Miller, Inc.
}

American Institute of Aeronautics and Astronautics 
resulting in limit on the turbopump engine life. Such issues have long been concerned with metallic blisks, resulting in the need for some form of frictional dampers for inserted blades.

For advanced aeronautics propulsion systems as illustrated in Figure 1, the ceramic composites are attractive for a number of reasons [4]. The high strength-to-weight ratio of ceramic composites helps to reduce engine weight and the one-piece construction of a blisk will result in fewer parts count, which should translate into reduced operational costs. Use of ceramic composites is also expected to add some internal damping to reduce the blade vibratory stresses. However, even CMC blisks may still be exposed to extremely high frequency dynamic excitation due to their structural response to high vibration environments. While the critical damping amount of approximately $2 \%$ [56 ] is required for the space shuttle main engine (SSME) turbopumps as an example, future propulsion systems may require even more.
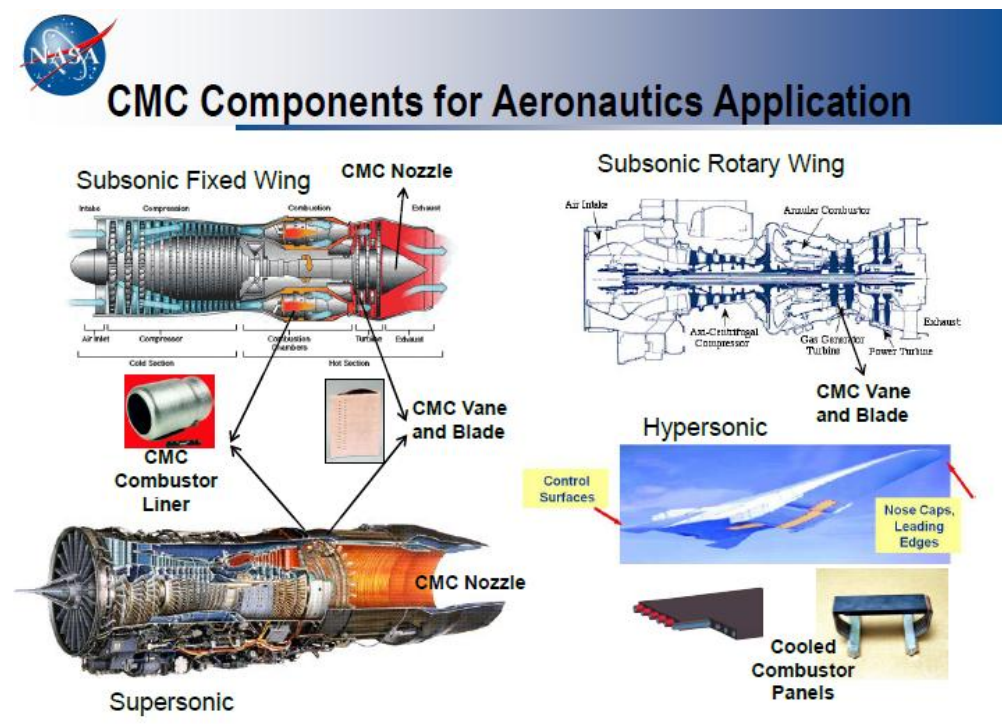

Figure 1: CMC Candidate Components for Aeronautics (Courtesy of NASA GRC)

The inherent damping capabilities of the CMC material systems remain largely unexplored and not understood. Such characteristics play an important role in the design and performance of turbine systems to manage unwanted vibrations. Vibrations particularly taking place at the natural frequency of the component are amplified through resonance, lead to component degradation, and potentially catastrophic engine failure.

Figure 2 displays a SSME turbopump turbine blade cracking along the 'fir-tree' attachment to the disk. The crack originated by high cycle fatigue (HCF) induced from blade vibration in bending mode. The amplitude of the alternating stresses caused by the vibrations combined with a locally high mean stress at the failure location exceeded the fatigue capability of the blade and resulted in crack initiation and growth. The issue was resolved through a modification of the frictional damper at the base of the blade and increases the viscous damping ratio to approximately $2 \%$. Other applications may require more or less damping than the amount of damping required for SSME since it is a function of design, materials selection, and operational parameters.
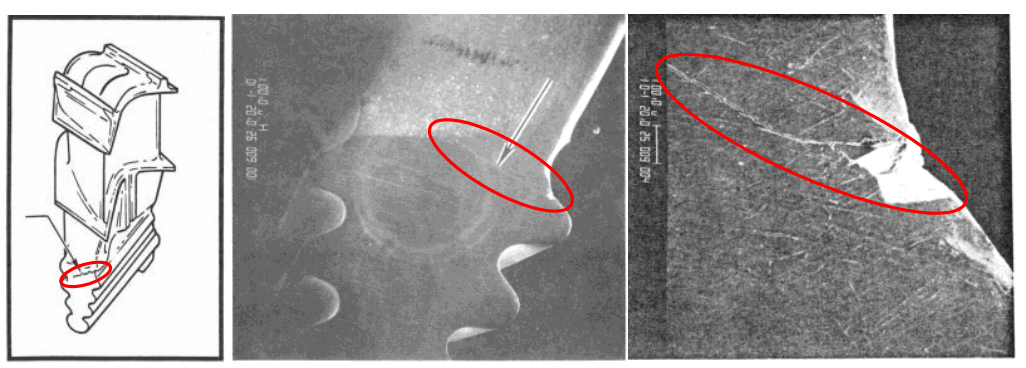

Figure 2: Metallic Turbine Blade Crack by Resonant Vibrations in Bending Mode (Courtesy of Boeing-Rocketdyne)

American Institute of Aeronautics and Astronautics 
The objective of this paper is to review some of the author's work on a carbon fiber-reinforced silicon carbide $(\mathrm{C} / \mathrm{SiC})$ system for the CMC turbine blisk development program and address an importance of the investigation of the blade vibration damping characteristics on candidate CMC material systems. SiC/SiC materials systems have also been identified as good candidates for vane and blade components in gas turbine engines with capability enhancements of reducing or eliminating cooling system, and reducing weights resulting in benefits of improved efficiency, reduced fuel burn, and reduced $\mathrm{CO}_{2}$ emission.

The goal of our current research is to characterize the vibration damping behaviors of candidate CMC material systems with 2-D and 3-D fiber architectures being considered for the next-generation aerospace turbomachinery engine development.

\section{Vibration Damping Characteristics of Carbon Fiber-Reinforced Silicon Carbide (C/SiC) System}

\section{II.1 Damping of Beam Specimens for Rocket Engine Turbomachinery Applications}

Vibration damping characteristics of $\mathrm{C} / \mathrm{SiC}$ were assessed by NASA Marshall Space Flight Center (MSFC) conducted room temperature damping tests of $\mathrm{C} / \mathrm{SiC}$ beam specimens produced using an isothermal chemical vapor infiltration (CVI) process. A new aluminum alloy 8009 beam specimen was also included in the test for comparison. The specimens represented a variety of fiber architecture reinforcements by varying the warp to fill fiber ratios while maintaining a constant total fiber volume fraction of $40 \%$ [1]. There were ten beam specimens listed in Table 1.

In order to obtain the modal frequency and damping values of the beam specimens, standard impact hammer testing was performed. Typically the accelerometer was mounted in one location and several impact locations were used to obtain the desired modes, this is known as roving the hammer. The typical testing configuration is shown in Figure 3. Points 2-4 were the hammer impact or drive points used to excite the modes of the beam. The accelerometer was bonded to the beam at point 1 . The specimens were suspended using elastic bands providing a free-free boundary condition.

Table 1: Beam Test Specimens

\begin{tabular}{|c|c|}
\hline Material & Vendor/Provided \\
\hline 8009 Aluminum & Allied Signal Metallic \\
\hline C/SiC $[0 / 90]$ & BP Chemical-HITCO \\
\hline C/C Uninhibited & BP Chemical-HITCO \\
\hline C/C Inhibited & BP Chemical-HITCO \\
\hline APC-2/AS4 & ICI Fiberite \\
\hline C/SIC 30\% Warp & DuPont/Rocketdyne \\
\hline C/SiC 40\% Warp & DuPont/Rocketdyne \\
\hline C/SiC 60\% Warp & DuPont/Rocketdyne \\
\hline C/SiC 70\% Warp & DuPont/Rocketdyne \\
\hline Inconel 718 & NASA Materials Lab \\
\hline
\end{tabular}

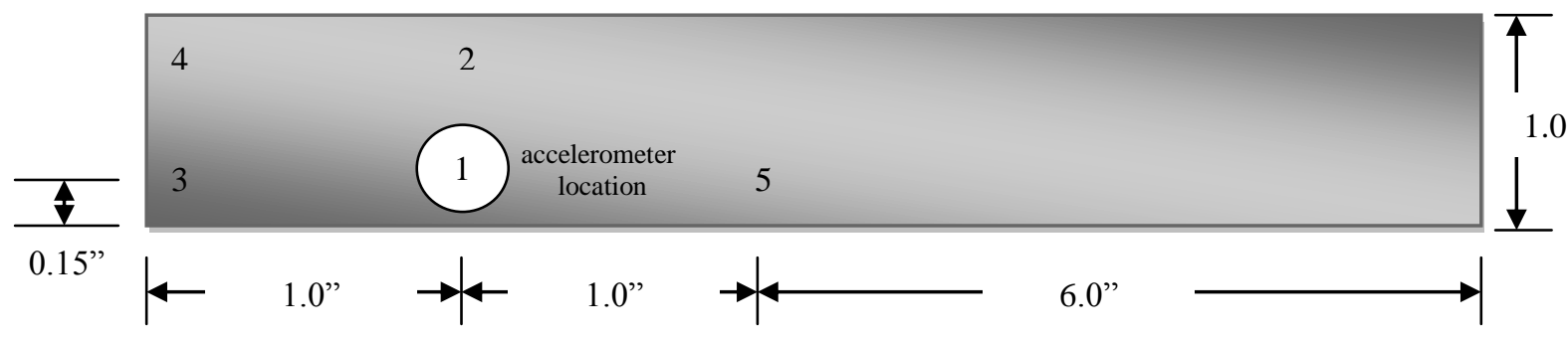

Figure 3: Sketch of Typical Beam Test Specimen Configuration 
There were several rounds of room temperature testing using the same test equipment. The force measurements were obtained using a small PCB model 086B 80 hammer and corresponding acceleration measurements acquired from a PCB model 353B17 accelerometer. The frequency and damping values were acquired using either HP model 5423A or 3565S Structural Dynamics Analyzer. Resonant frequencies were identified using broadband measurements then zoom measurements were used to provide greater resolution for damping estimates from the frequency response functions (FRF). The damping capacity calculated in percent critical damping factor (viscous damping ratio).

Figure 4 shows the results from a series of tests. Damping values were compared to Inconel 718 specimen as a baseline representing typical super-alloys. The $\mathrm{C} / \mathrm{SiC}$ samples had different amounts of fibers in the warp direction than the fill direction for a [0/90] layup. It can be seen that directional fiber volumes (warp to fill percentages) with a [0/90] architecture show different damping values for different modes. Results showed that the damping values of the $\mathrm{C} / \mathrm{SiC}$ specimens are an order of magnitude greater than that of the metallic baseline Inconel 718 alloy. The average critical damping of the CMC is approximately $0.2 \%$ vs. approximately $0.01 \%$ percent for Inconel 718 . It was also observed that the first torsional mode produced the most damping in all specimens.

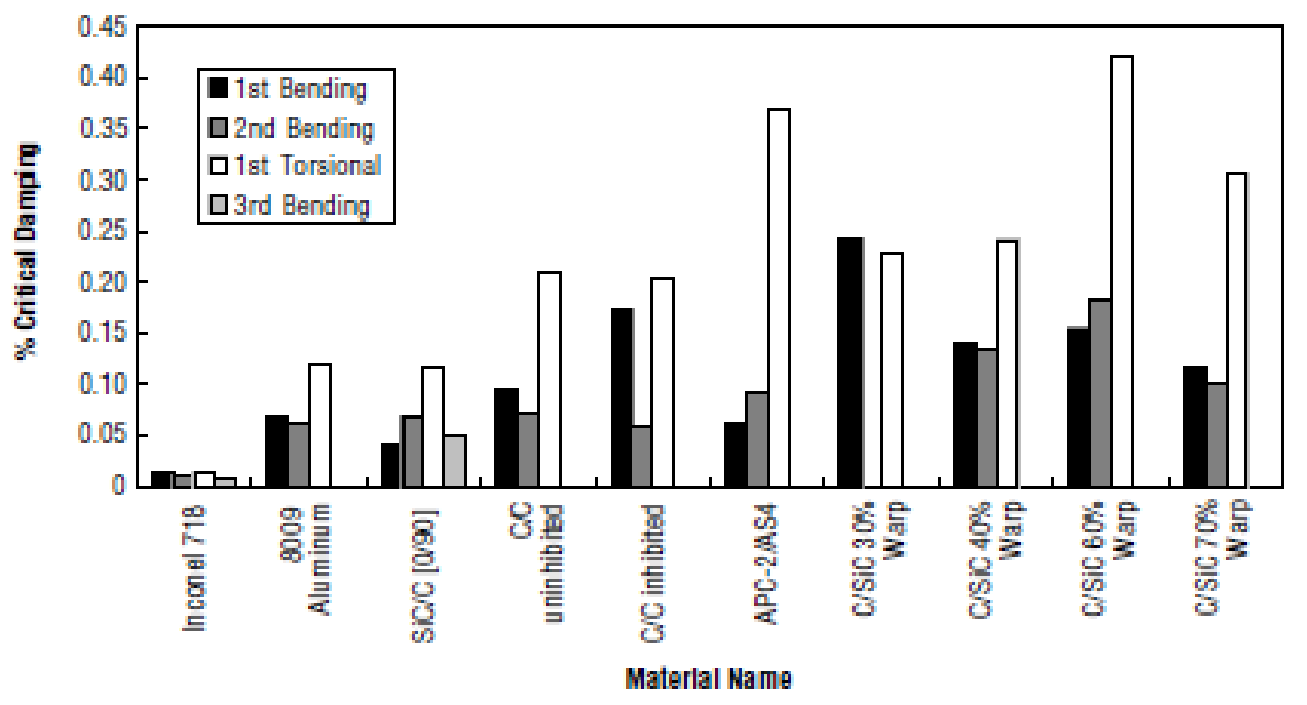

Figure 4: Critical Damping of Test Beam Specimens

As can be seen in Figure $4_{2}$ although CMC has a greater vibration damping capability, it is also indicated that CMC damping is heavily design and application dependent. It is a very crucial step to select the best materials system with proper fiber architectures for a specific application to be designed. Such as the SSME turbopump blade vibration damping requirement, the value of $0.2 \%$ of the CMC damping falls short of $2 \%$ damping of the current frictionally damped metallic blades.

\section{II.2 Damping of SIMPLEX Turbopump C/SiC Blisk}

The NASA SIMPLEX Turbopump Blisk program generated substantial data for $\mathrm{C} / \mathrm{SiC}$ damping characteristics with an integrally bladed disk (blisk) in turbine component [7]. A program was designed to implement a ceramic matrix composite blisk into rocket engine. The NASA-MSFC, utilizing the MSFC turbomachinery design, analysis, and testing along with materials development from both NASA Glenn Research Center (GRC) and MSFC, tested two $\mathrm{C} / \mathrm{SiC}$ blisks in the SIMPLEX Turbopump at NASA-MSFC Test Stand shown in Figure 5. The program performed three separate test series. The first series was to validate that the SIMPLEX turbopump was correctly rebuilt to the existing turbopump. The test series was to weed out any turbopump design and manufacturing flaws or fatigue issues prior to putting the $\mathrm{C} / \mathrm{SiC}$ blisks into it. The second and third series were the $\mathrm{C} / \mathrm{SiC}$ blisk test series. The primary goal of these series was to expose the blisks to as much fatigue causing dynamic stress as possible to examine the material's capability with the turbopump design speed.

One blisk was constructed with a polar woven fiber perform and second blisk was constructed with a quasiisotropic perform [7]. A complete $\mathrm{C} / \mathrm{SiC}$ blisk is shown in Figure 6. 


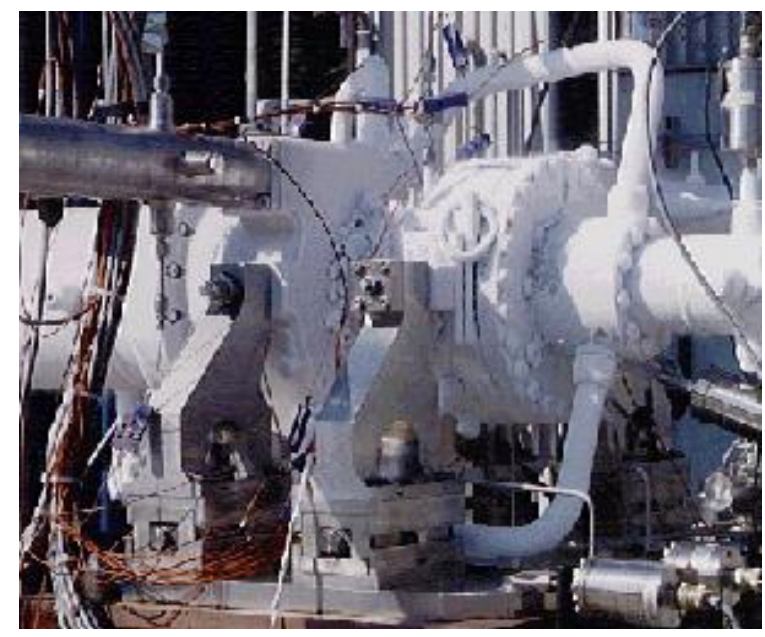

Figure 5: SIMPLEX turbopump (chilled down prior to testing)

(Courtesy of NASA MSFC)

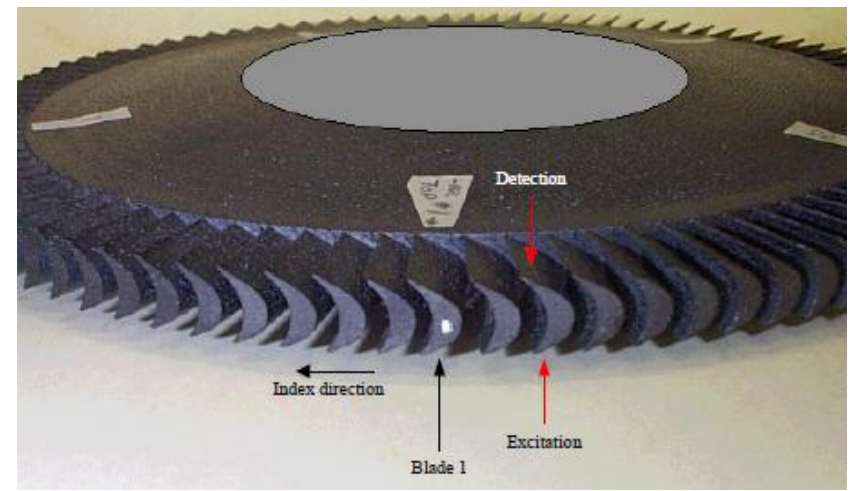

Figure 6: Photo of SIMPLEX turbopump blisk (Courtesy of NASA MSFC)

Each blisk was manufactured with an approximate $40 \%$ fiber volume fraction. The frequency and damping properties of both of the blisks subjected to a room temperature were measured by Argonne National Laboratory [8] with specimen conditions of as fabricated, after proof spun and pump tested at NASA-MSFC. Specific damping capacity (SDC) was determined for each blade based on a single resonant frequency.

In order to determine the individual blade frequency of interest, the finite element (FE) results as shown in Figure 7 were used as a starting point.
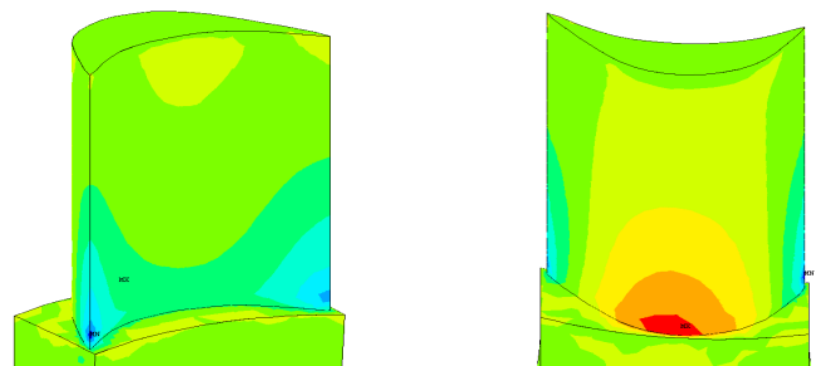

Figure 7: Stress Contours Calculated by FE for Blade Vibration First Bending Mode (Excess stresses are shown at the blade/platform region of blade.) 
In the region of the FE predicted frequency, resonant frequencies were obtained as a function of blade number. Each blade was excited by an impact hammer manually and electronically. The response was measured electronically and damping calculations were performed by examining the decay envelope of the mode of interest to calculate the specific damping capacity (SDC) defined by $\psi=4 \pi \zeta$, where: $\psi=$ the specific damping capacity, $\zeta=$ viscous damping ratio (percent critical damping). The normalized natural frequency and SDC of a quasi-isotropic blisk test specimen are shown for each individual blade in Figures 8 and 9, respectively for the as-fabricated, post proof test, and post pump test conditions. It is shown that resonant peaks and SDC varied significantly from blade to blade [9]. An image of a blisk prior to pump test from the computed tomography (CT) is shown in Figure 10 which displays density variation significantly from blade to blade as well. It should be noted that actual damping values of the NASA blisks was normalized by an undisclosed factor in order to comply with International Traffic in Arms Regulations (ITAR) restrictions.

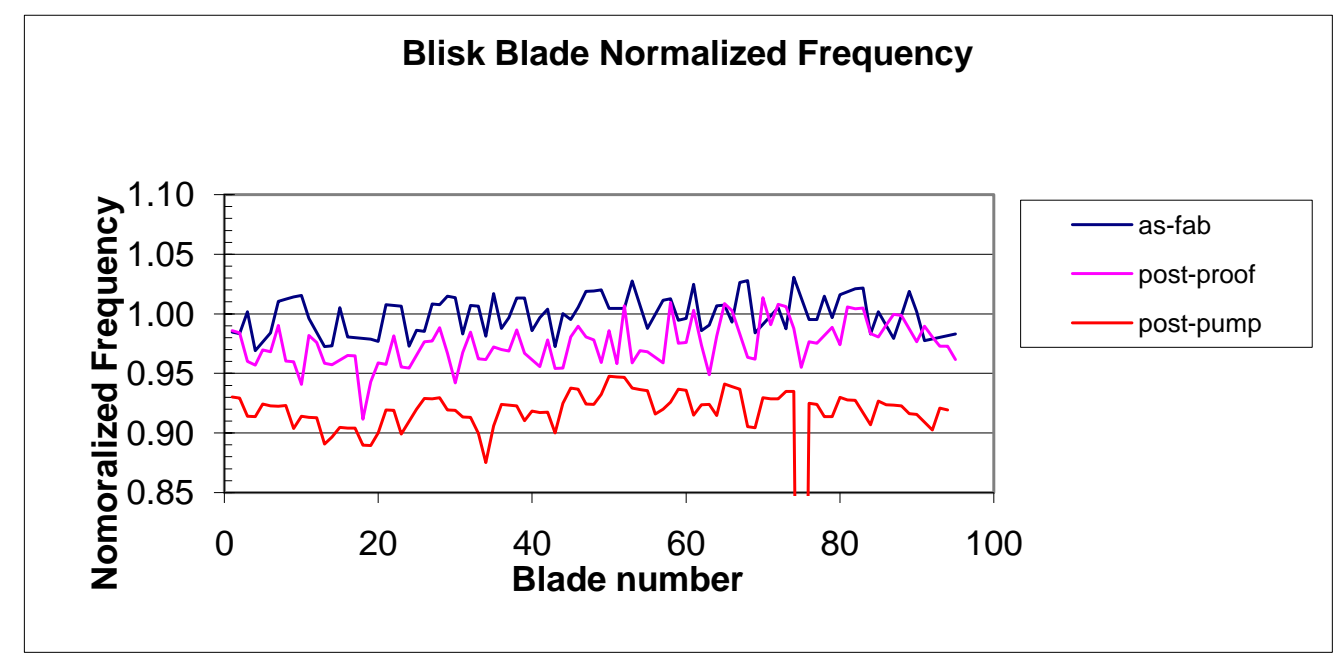

Figure 8: SIMPLEX CMC Blisk Normalized Frequency for Test Conditions

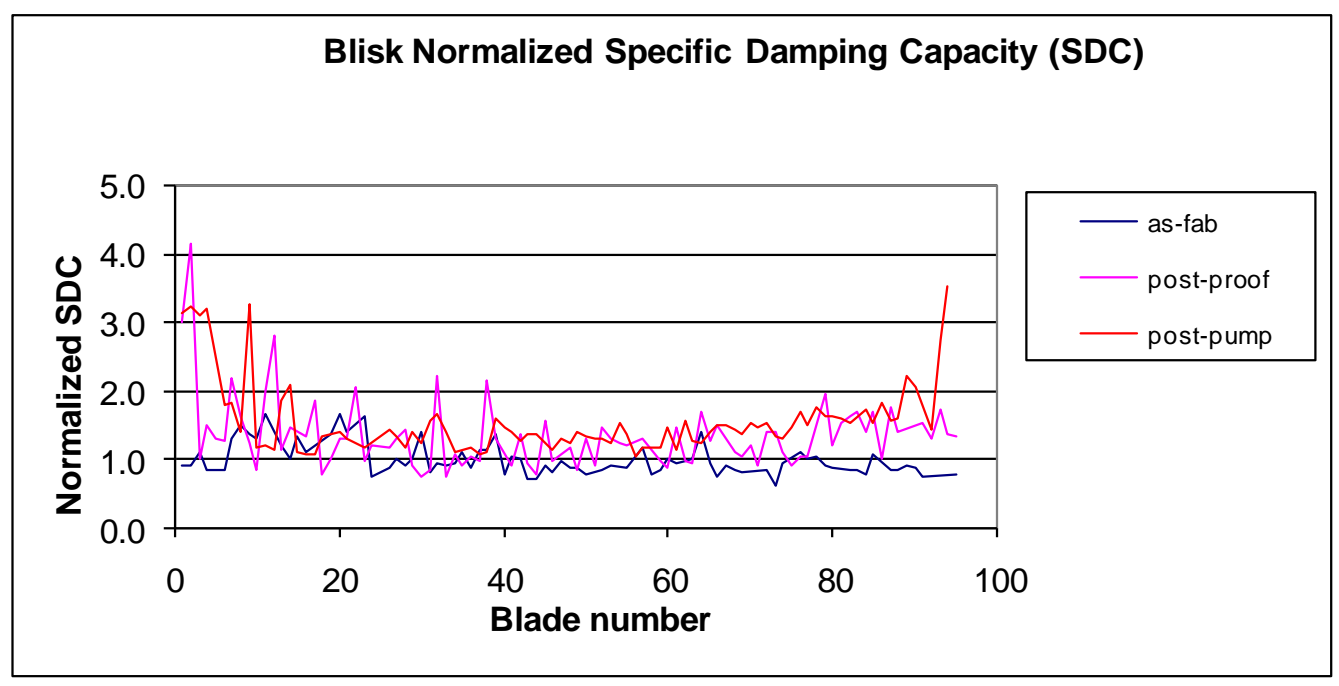

Figure 9: SIMPLEX CMC Blisk Normalized SDC for Test Conditions 


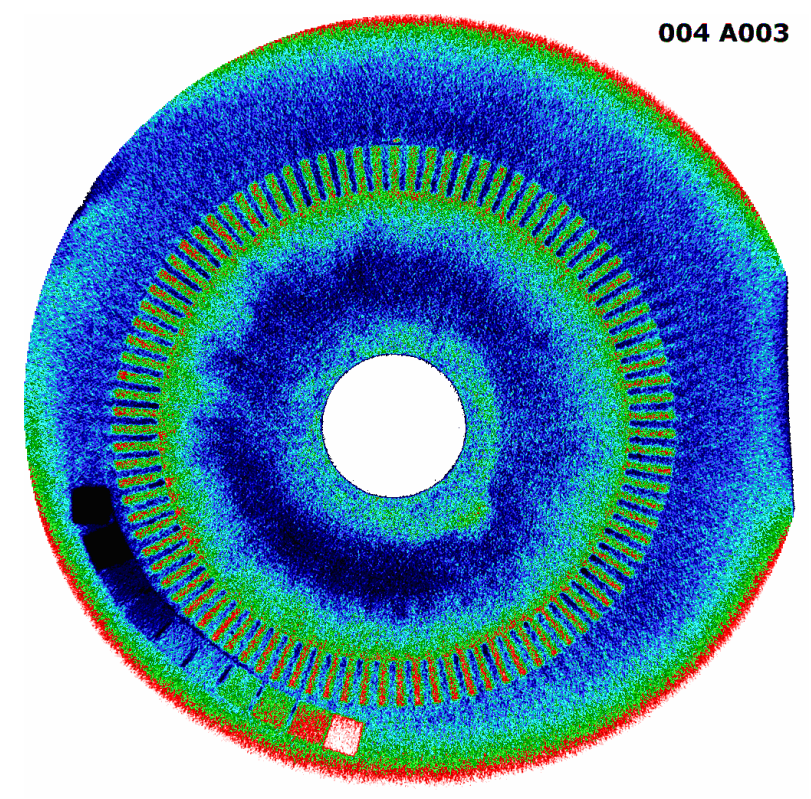

Figure 10: Computed Tomography (CT) Image of Polar Woven C/Sic Blisk Showing Density Variations from Blade to Blade (Courtesy of NASA MSFC)

While the data were significantly scattered in damping behavior of all three test conditions and the general trend failed to be consistent for each individual blade, Figure 9 showed an overall increase in the viscous damping after proof and pump tests relative to the as-received condition. Perhaps microcracking of the matrix after proof and pump tests produced higher damping due to the damage. Similar data scatters were observed from the results of the polar woven blisk tests. The damping capacity of a quasi-isotropic fiber blisk and a polar woven fiber blisk is shown in Figures 11 and 12, respectively after spin tests. A polar woven fiber blisk demonstrated a noticeable increasing trend in damping capacity. A polar woven fiber blisk showed approximately increase of $20 \%$ of the damping capacity relative to a quasi-isotropic fiber blisk.

While these results seem to demonstrate a CMC blisk damping capability with an order of magnitude greater than that of Inconel 718 alloy blisk, the $\mathrm{C} / \mathrm{SiC}$ blisks studied in this program did not show sufficient damping for applications like SSME which requires a blade vibration damping of $2.0 \%$.

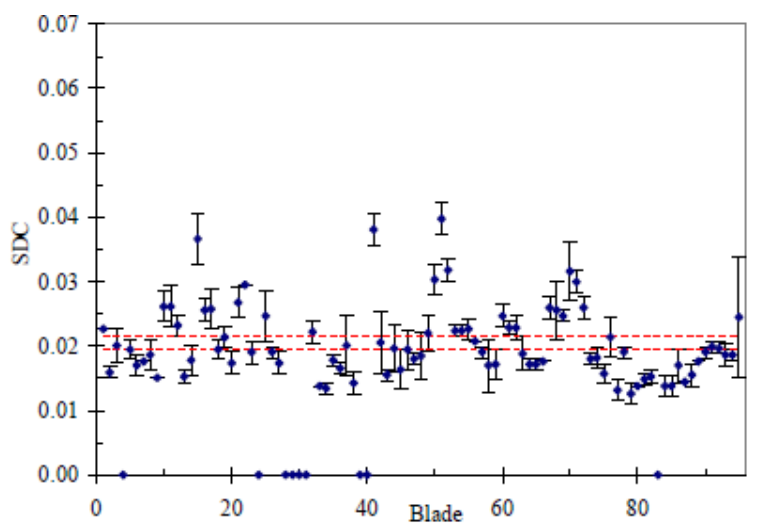

Figure 11: Normalized SDC of Quasi-isotropic Blisk

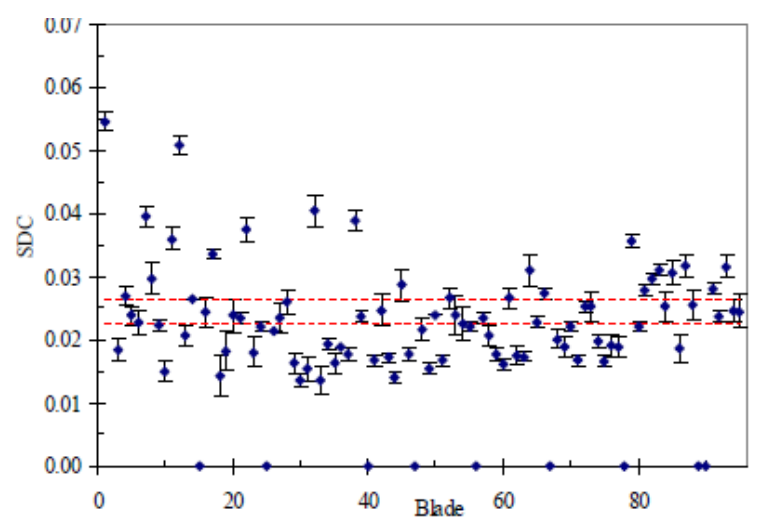

Figure 12: Normalized SDC of Polar Woven Blisk 


\section{II.3 Damping of 3-D Reinforced C/SiC Beam Specimens for RS-2200 Linear Aerospike Engine Applications}

NASA-GRC and Foster-Miller studied damping of 3-D reinforced $\mathrm{C} / \mathrm{SiC}$ material systems to quantify the inherent material damping of several $\mathrm{C} / \mathrm{SiC}$ materials considered to manufacture the Reusable Launch Vehicle (RLV) Linear Aerospike Engine (Fig. 13) RS-2200 fuel turbopump turbine blades [10]. The test materials were reinforced with both 2-D braid and 3-D braid and infiltrated using a pre-ceramic polymer infiltration and pyrolysis (PIP) process. While 3-D braid potentially provides superior toughness and mechanical properties compared with 2$\mathrm{D}$ reinforced materials, very little work was done with 3-D reinforced $\mathrm{C} / \mathrm{SiC}$ materials, particularly in the area of vibration damping characterization.
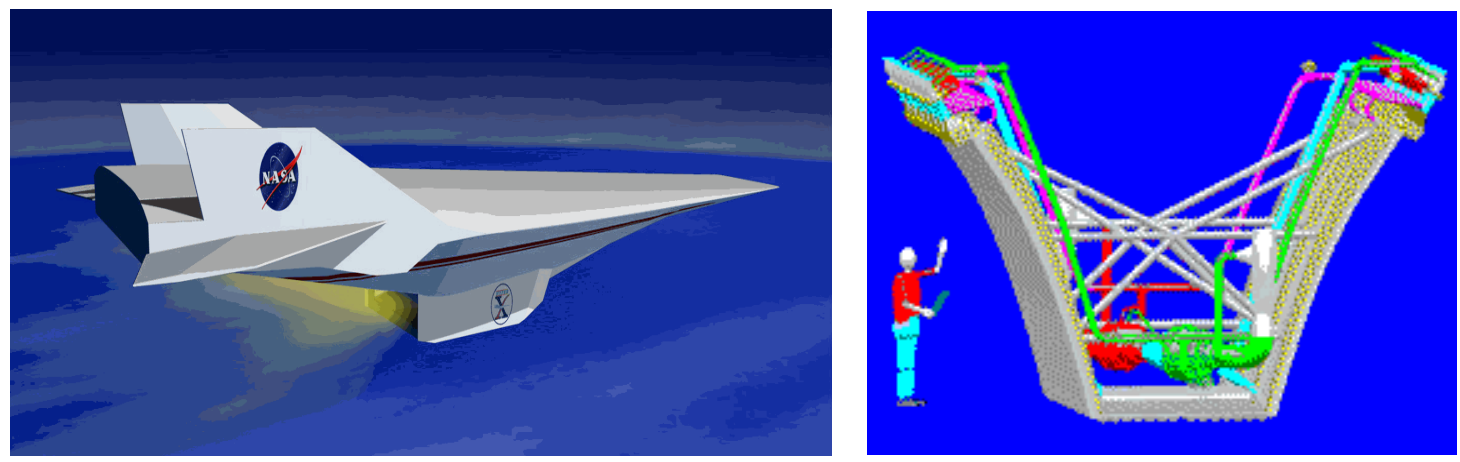

Figure 13: Illustration of Linear Aerospike Turbopump Rocket Engine (Courtesy of NASA MSFC)

Damping often varies as a function of both strain and frequency. Therefore, it is important to measure damping in a realistic environment that simulates the dynamic state of a component as closely as possible. Dynamic test samples were designed and manufactured to represent the expected geometry and behavior of a realistic turbopump turbine with high natural frequency in this study. The test specimens were tailored to represent the behavior of a smaller, but closely related turbopump turbine.

A number of test specimens were manufactured using a 2-D laminated structure with woven and braided fabric, and a 3-D braided structure by Foster-Miller. The specimens were tested for forced dynamic response using measured surface strain as a response. The samples were clamped in a base block and excited with mini-shaker. Damping was obtained from the system transfer function. A sketch of the specimen design is shown in Figure 14.

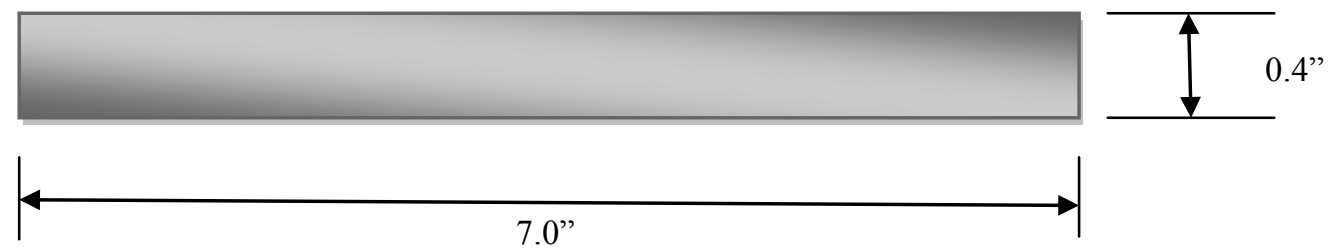

Figure 14: Sketch of RS-2200 Blade-Damping Specimen

The 2-D specimens were reinforced using both woven and triaxially braided T300 carbon fabric. The 3-D braid was produced with T300 carbon fiber using Foster-Miller's unique three-dimensional braider. A photo of the typical test specimen is shown in Figure 15.

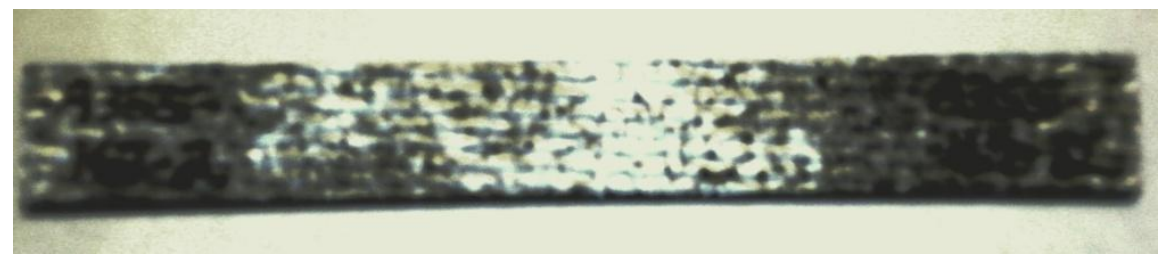

Figure 15: Photo of Blade-Damping Test Specimen 
A number of the 2-D reinforced specimens, including all of the specimens reinforced with the plain weave fabric completely delaminated. The samples reinforced with 3-D braid suffered no delaminations or any apparent ill effects. This result demonstrated one of the advantages of 3-D braided reinforcement over 2-D reinforcement superior handling and processing characteristics. A photo of a completed 3-D reinforced sample is shown in Figure 16.

A specimen length of 7 inches was chosen to produce a double cantilevered bar with a nominal length 3 inches on either side with 1 inch of clearance in the center to clamp the bars. The resonant bending frequencies for a clamped bar were predicted by FE models. The 3 inches long bars were predicted to have a first bending mode frequency of $550 \mathrm{~Hz}$.

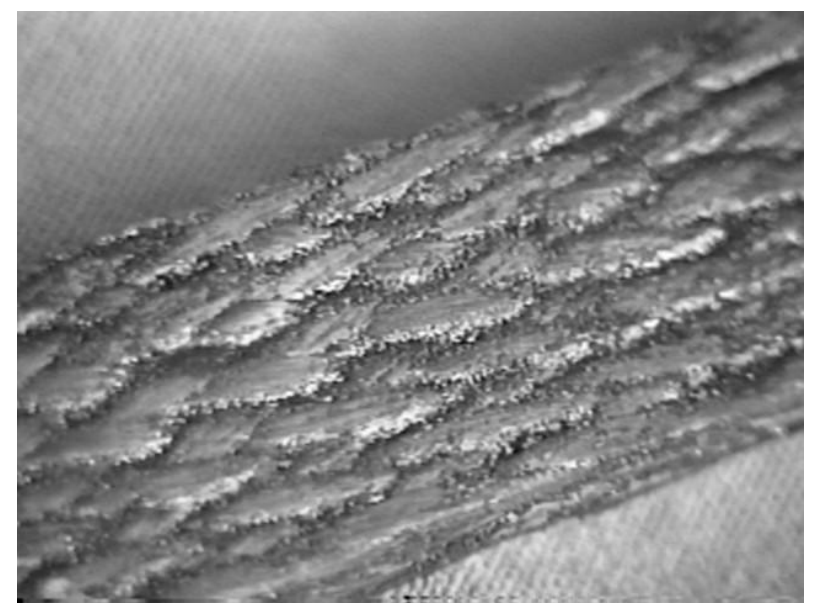

Figure 16: Photo of 3-D Braided C/SiC Damping Specimen Surface

Measurements were performed using forced excitation with a cantilevered beam setup, a common approach for damping measurements. An illustrative sketch of the test setup is shown in Figure 17.

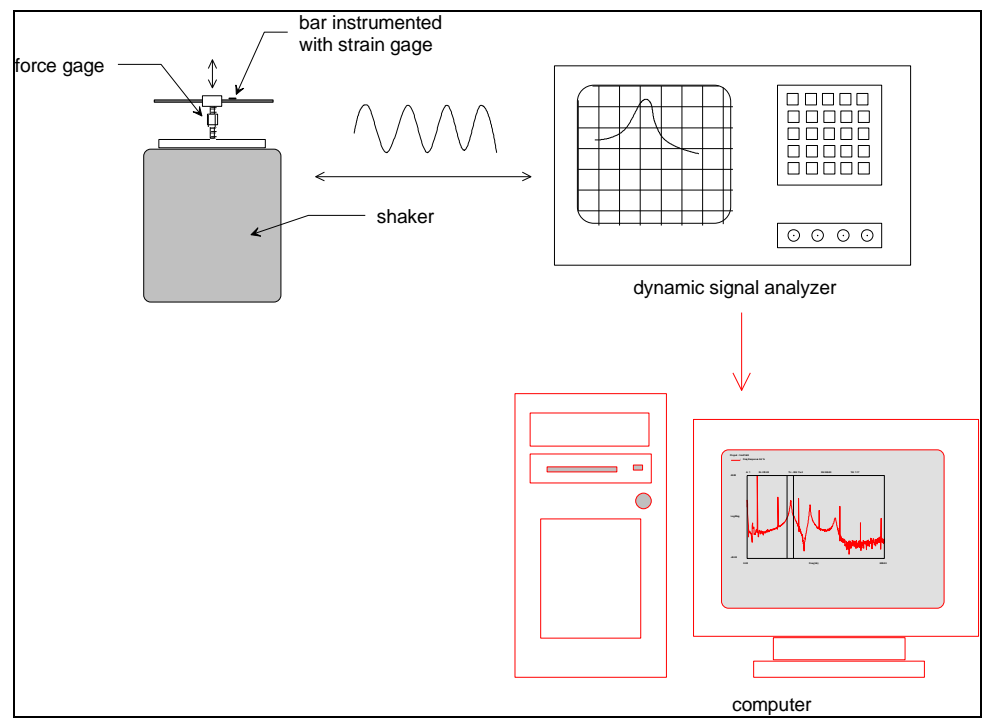

Figure 17: Sketch Showing Dynamic Test Setup

There is often a misconception that material damping is constant and that it is possible to quantify damping with one number. Damping of the first bending mode of a bar can differ from the damping of the first torsional mode or even the second bending mode as seen in Section II.1. Damping measured from the 3-D reinforced C/SiC samples 
are shown in Figure 18 in the form of \% critical damping as a function of frequency. All measurements represent flexural damping measured from the first bending mode.

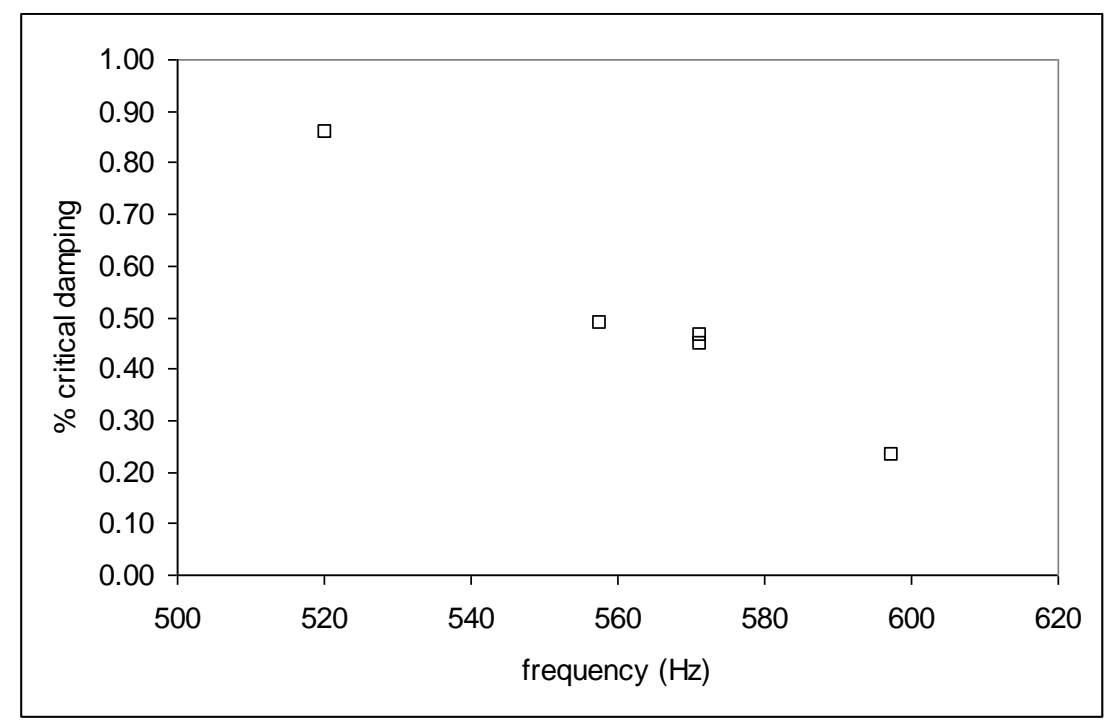

Figure 18: Critical Damping of 3-D Braided C/SiC Specimens as Function of Frequency

Measured damping of the 3-D reinforced samples showed a strong dependance on natural frequency. Maximum measured damping was equal to $0.85 \%$ at $520 \mathrm{~Hz}$. The minimum measuerd damping was $0.2 \%$ at $600 \mathrm{~Hz}$.

\section{Summary and Remarks}

The intent of this paper is to review some work on $\mathrm{C} / \mathrm{SiC}$ vibration damping by the authors for the NASA CMC turbine blisk development program, to address an importance of the further research of the blade vibration damping characteristics on candidate CMC material systems, and to bring novel concepts and methods that are capable of providing the CMC vibration damping targets required for the NASA's advanced engine systems.

The objective of our research was to characterize the vibration viscous damping behavior of $\mathrm{C} / \mathrm{SiC}$ composites. $\mathrm{C} / \mathrm{SiC}$ samples were produced using a PIP process and a CVI process. The vibration damping properties were measured and calculated. While the critical damping amount of approximately $2 \%$ is required for typical aerospace turbomachinery engines such as the SSME turbopumps, damping amount at high frequencies was less than $0.2 \%$. Damping appeared to decrease with an increase in the natural frequency. Advanced high-performance aerospace propulsion systems certainly will require even more damping than what current systems require.

Results of 2-D and 3-D reinforced $\mathrm{C} / \mathrm{SiC}$ bench-top test specimens and $\mathrm{C} / \mathrm{SiC}$ blisk specimens manufactured with quasi-isotropic and polar woven fiber architectures for the actual NASA SIMPLEX turbopump test showed that the material is very lightly damped, with a highly frequency dependent damping, decreasing with increasing frequency. The source of the damping is uncertain, although fiber/matrix interface friction may play a large role.

The results presented in this paper indicate that external or internal damping treatments will be required to improve high temperature engine durability and safety by completely evaluating dynamic properties, for instance damping capacity and resonant frequency along with the effects of mechanical events such as fatigue wear of fiber and matrix, environmental events such as thermal shock and oxidation, and combined mechanical and environmental conditions. Common external damping treatment such as "Coulomb" (or dry-friction) damping may not be a practical choice for CMC composite blades. Coulomb damping is due to friction between sliding planes in contact. Perhaps internal damping treatment for improving viscous damping (inherent material damping) would be a more reasonable method for the CMC blade damping increase and real engine applications.

The use of ceramic matrix composites seems to be clearly a requirement in the design of the advanced high performance aerospace engines. However, adequate understanding of their properties in highly loaded engine systems is lacking in general. There is the wide variability in the construction of the composite 
layers, the lack of a capability to predict the stresses in these structures due to random loading, and an inability to accurately identify the enormous dependence of the basic material properties of the structures due to thermo mechanical-environmental conditions. These inadequacies in our understanding such as vibration damping capability can cause the structural loads to be mischaracterized to an unacceptable level.

While results from our study showed that the damping values of the $\mathrm{C} / \mathrm{SiC}$ specimens are an order of magnitude greater than that of the baseline super-alloy metals, damping is an important design parameter that should not be overlooked from the beginning of a selection process of the CMC matrix/fiber combination systems that essentially should be thermomechanically and chemically compatible under severe environmental and dynamic loading conditions. It is required to complete understanding of the vibration damping properties of CMCs to a degree where they can be considered truly "engineering" structures, capable of being used in advanced high-performance aerospace turbomachinery engine design such that dynamic loads and stresses can be determined accurately and confidently. Efforts should also be made to improve the challenges in manufacturing technology itself. Additionally the incorporation of "smart" structural element such as high-temp piezoelectric such that material stiffness and vibration damping of the CMC blades can be actively controlled to reduce unwanted blade vibrations would be a potential idea as well.

\section{Acknowledgments}

The authors thank G. Genge, M. Effinger, and K. Mims of NASA-MSFC for discussions on CMC SIMPLEX turbine blisk program and other space rocket engine applications. The authors also thank M. Petervary of BoeingRocketdyne for information on SSME turbopump turbine blade damping, O. Mehmed of NASA-GRC on aircraft gas turbine engine blade damping, and Dr. A. Misra of NASA-GRC for information on CMC aeronautics applications.

\section{References}

1. J. W. Brockmeyer, G. D. Schnittgrund: Fiber-Reinforced Ceramic Composites for Earth-to-Orbit Rocket Engine Turbines, Phase I - Final Report, Lewis Research Center, Cleveland, OH, NASA CR-185264, 1990

2. J. W. Brockmeyer: Fiber-Reinforced Ceramic Matrix Composites for Earth-to-Orbit Rocket Engine Turbines, Phase II - Final Report, Lewis Research Center, Cleveland, OH, NASA CR-198526, 1996.

3. T. P. Herbell, A. J. Eckel, J. W. Brockmeyer, M. R. Mitchell: Ceramic Composites Protend Long Turbopump Lives, 1993 SAE Aerospace Atlantic Conference, SAE Paper No. 931372, April, 1993.

4. A. K. Misra: Overview of CMC Research at GRC, October, 2010.

5. M. Petervary: Internal Communication on SSME turbopump blade damping, NASA/Boeing-Rocketdyne, 2001.

6. O. Mehmed: Internal Communication on aircraft gas turbine engine blade damping, NASA-GRC, 2004.

7. G. Genge, K. Mims, M. Effinger, D. Harris, J. Min, R. Sullivan, R. Beshears, M. Halbig: Development of a Ceramic Matrix Composite Integrally Bladed Disk for Use in the SIMPLEX Turbopump, JANNAF, Albuquerque, New Mexico, December, 1996.

8. W.A. Ellingson, et al: Recent Results of Applying Several NDE Methods to C/SiC Blisks for the SIMPLEX Turbopump, 23rd Annual Conference on Composites, Materials, and Structures, Cocoa Beach, FL, January, 1999.

9. M. Effinger, W. Ellingson, T. Spohnholtz, J. Koenig: Concept for Determining the Life of Ceramic Matrix Composites Using Non-Destructive Characterization Techniques, $4^{\text {th }}$ Conference on Aerospace Materials, Processes, and Environmental Technology (AMPET), Huntsville, Alabama, September, 2000.

10. T. Campbell, J. Ting, J. Min, P. Avitabile: Dynamic Properties of 3-D Reinforced C/SiC for RS-2200 Linear Aerospike Engine, 29th Conference on Advanced Ceramics and Composites, Cocoa Beach, FL, January, 2000. 